nông, siêu âm có dịch), tách vết mổ dùng kháng sinh giảm viêm theo dõi, sau 2 tuần giảm hết triệu chứng. Một ca chảy máu tại vết mổ phải tách vết mổ đển cân cơ lấy máu cục cầm máu điều trị kháng sinh và thuốc transamine. Một ca bệnh nhân tựt thấp lưới ở lỗ bẹn nông (cảm giác tức khi đứng, thăm lỗ bẹn nông thây lưới ngay lỗ bẹn nông do lỗ bẹn này khá rộng và mỏng của thoát vị trực tiếp nhưng theo dổi tiếp không thấy di chuyển thêm dù ho rặn mạnh. Những lần khám sau thấy lưới vẫn dính chắc và cảm giác khó chịu khi vận động không còn. Chúng tôi khuyến cáo nên hạn chế sức ép quá mức và kéo dài như không ho rặn, vận động hoặc đứng lâu trong thời gian 2 tuần đâu đối với đặt lưới tự dính. Kết quả là khả quan so với tình hình chung. ${ }^{3,4}$

Tai biến trong mổ không gặp ca nào. Có 2 ca viêm nề vùng bìu là do bóc tách xa bao thoát vị lớn mắc dù trước khi khâu kiểm tra các thành phần bình thường nhưng sau mổ vẫn sưng vài ngày và khỏi khi điều trị. Số ngày đau sau mổ, số ngày nằm viện và kết quả khám lại sớm sau một tháng cho thấy kết quả tốt của cả lô nghiên cứu.

\section{KẾT LUÂ̂N}

Phẫu thuật Lichtenstein điêu trị thoát vị bẹn bằng tấm lưới tự dính Parietex Progrip Covidien tại các bệnh viện vùng đồng bằng tỉnh Thanh hóa có kết quả bước đâuu cho thấy đối tượng hầu hết là bệnh nhân trung cao tuổi có bệnh hô hấp kèm theo chọn giải pháp mổ mở. Phẫu thuật không có tai biến trong mổ, kỹ thuật đặt lưới thuận lợi an toàn, không phải khâu nên không ảnh hưởng các nhánh thần kinh. Yêu cầu lưới đặt phải áp thật tốt ngay theo chiều cong giải phẫu vùng ben để tránh di lêch cuôn hay gấp nếp. Biến chứng sau mổ ít và hầu hết khắc phục bảo tồn. Kết quả sớm cho thấy không tái phát không đau mạn tính sau mổ.

\section{TÀI LIỆU THAM KHẢO}

1. Fang Z, Zhou J, Ren F, Liu D. Self-gripping mesh versus sutured mesh in open inguinal hernia repair: system review and meta-analysis. American journal of surgery. 2014;207(5):773-781. doi:10.1016/j.amjsurg.2013.08.045

2. Wang $\mathbf{Y}$, Zhang $\mathbf{X}$. Short-term results of open inguinal hernia repair with self-gripping Parietex ProGrip mesh in China: A retrospective study of 90 cases. Asian Journal of Surgery. 2016;39(4):218 224. doi:10.1016/j.asjsur.2015.05.001

3. Voyles C. R. Outcomes analysis for groin hernia repairs. Surg Clin North Am. 2003;83(5):1279.

4. Porrero $\mathrm{JL}$, Cano-Valderrama $\mathrm{O}$, Castillo $\mathrm{MJ}$, Alonso MT. Proposed technique for inguinal hernia repair with self-gripping mesh: avoiding fixation to undesired structures. Hernia: the journal of hernias and abdominal wall surgery. 2015;19(5):771-774. doi:10.1007/s10029-014-1315-8

5. Köhler G, Lechner M, Mayer F, et al. SelfGripping Meshes for Lichtenstein Repair. Do We Need Additional Suture Fixation? World journal of surgery. doi:10.1007/s00268-015-3313-0

6. Lechner MN, Jäger $T$, Buchner $S$, Köhler G, Öfner $D$, Mayer F. Rail or roll: a new, convenient and safe way to position self-gripping meshes in open inguinal hernia repair. Hernia: the journal of hernias and abdominal wall surgery. 2016;20(3):417-422. doi:10.1007/s10029-0151389-y

7. Rosenberg J, Andresen K. The Onstep Method for Inguinal Hernia Repair: Operative Technique and Technical Tips. Vilallonga $R$, ed. Surgery Research and Practice. 2016;2016:6935167. doi:10.1155/2016/6935167

\title{
ĐÁNH GIÁ KẾT QUẢ PHẪU THUâ̂T GẪY LIÊN MẤU CHUYỂN XƯƠNG ĐÙI Ở NGƯờI CAO TUỔI TẠI BỆNH VIỆN ĐA KHOA TỈNH THÁI BÌNH
}

\section{Đào Văn Dương*, Trần Văn Hoàng*, Nguyễn Văn Dũng*}

\section{TÓM TẮT}

Mục tiêu: Nhận xét đặc điểm lâm sàng, XQ và đánh giá kết quả điều trị phẫu thuật gãy liên mấu chuyển (LMC) xương đùi ở người cao tuổi có sử dụng màn tăng sáng tại Bệnh viện Đa khoa tỉnh Thái Bình. Phương pháp nghiên cứu: mô tả tiến cứu không đối

*Bệnh viện đa khoa tỉnh Thái Bình

Chịu trách nhiệm chính: Đào Văn Dương

Email: daoduong24@gmail.com

Ngày nhận bài: 24.2.2021

Ngày phản biên khoa hoc: 30.3.2021

Ngày duyệt bài: 9.4.2021 chứng. Kết quả: 67 bệnh nhân nghiên cứu với tuổi trung bình là $73,76 \pm 5,25$. Liền vết mổ kỳ đâu: $67 / 67$ bênh nhân $(100 \%)$. Kết quả nắn chỉnh: Xương được nẳn về đúng vị trí giải phẩu, góc cổ thân $125^{\circ}-130^{\circ}$ có $50 / 67 \mathrm{BN}(74,62 \%)$. Từ $120^{\circ}-<125^{\circ}$ có $12 / 67 \mathrm{BN}$ $(17,91 \%)$, từ $110^{0}-<120^{\circ}$ có 5 BN $(7,47 \%)$. Kết quả xa theo tiêu chuẩn của Nguyễn Trung Sinh của chúng tôi tốt và rất tốt chiếm $88.05 \%$, tỉ lệ đạt trung bình là $11,95 \%$ và không gặp bệnh nhấn nào có kết quả xấu.

Tư khóa: gãy xương, liên mấu chuyển xương đùi, phẫu thuật

\section{SUMMARY \\ EVALUATETHESURGICALTREATMENT REUSLT}


OF INTERTROCHANTERIC FRACTURE IN ELDERLY AT THAI BINH GENERAL HOSPITAL

Objectives: Describe the clinical, radiographic characters and evaluate the surgical treatment result of intertrochanteric fracture in elderly at Thai Binh general hospital. Method: prospectively. Result: 67 patients with average age is $73.76 \pm 5.25$, all of patients were not infected. Result of reduction: angle of inclinnation $125^{\circ}-130$ was $74.62 \%$, from $120^{\circ}-<125$ was $17.91 \%$, from $110^{\circ}-<120$ was $7.47 \%$. Arcoding to Nguyen Trung Sinh score, the excellent and good results are $88,05 \%$ and no patient had bad result.

Keys words: fracture, intertrochanteric, surgical

\section{I. ĐẶT VẤN ĐỀ}

Gãy liên mấu chuyển xương đùi là loại gãy xương nặng, thường gặp ở người cao tuổi bị loãng xương và có các bệnh lý nội khoa đi kèm. Chính vì vậy, việc điêu trị thường khó khăn nhất là vấn đề phục hồi chức năng. Mục tiêu điều trị của gãy xương vùng mấu chuyển xương đùi là cố định xương đủ vững chắc. Chúng tôi sử dụng nẹpvít nén ép trượt (DHS) để kết hợp xương gãy liên mấu chuyển nhưng đặc biệt có sự hố trợ quan trọng trong mổ của màn tăng sáng ( $C$-arm) giúp cho vị trí đă̆t nẹp vít chính xác, xâm lấn phần mềm tối thiểu, thời gian mổ rút ngắn tối đa mang lại kết quả bước đầu rất khả quan cho bệnh nhân.

\section{II. ĐỐI TƯợNG VÀ PHƯƠNG PHÁP NGHIÊN CỨU}

2.1 Đối tượng nghiên cứu: bao gồm 67 trường hợp gãy liên mấu chuyển xương đùi được điều trị phẫu thuật bằng phương pháp kết hợp xương nẹp DHS bằng kỹ thuật ít xâm lấn có sử dụng màn tăng sáng.

2.2 Phương pháp nghiên cứu: Tiến cứu mô tả không đối chứng

2.3 Thu thập xử lí số liệu: bằng phần mềm SPSS 16.0

\section{KẾT QUẢ NGHIÊN CỨU}

Đặc điểm gãy LMC xương đùi theo nhóm tuổi và giới $(\mathrm{n}=67)$

\begin{tabular}{|c|c|c|c|c|}
\hline Tuổi Giới & Nam & Nũ̃ & Cộng & $\begin{array}{c}\text { Tỷ lề } \\
\%\end{array}$ \\
\hline $60-69$ & 14 & 6 & 20 & 29,85 \\
\hline $70-79$ & 2 & 10 & & 46,26 \\
\hline$\geq 80$ & & 5 & & 23,89 \\
\hline & & & 100 & 100 \\
\hline
\end{tabular}

Trong nghiên cứu của chúng tôi tỉ lệ nam giới bị gãy LMC chiếm $68,65 \%$ và nữ giới chiếm $31,35 \%$. Lứa tuổi từ $70-79$ tuổi bị gãy LMC chiếm nhiêu nhất là 46,26\%.

Phân loại theo gẫy liên mấu chuyển theo AO $(n=67)$

\begin{tabular}{|c|c|c|c|c|c|}
$\begin{array}{r}\text { Nhóm } \\
\text { tuổi } \\
\text { Phân loạii }\end{array}$ & $\begin{array}{c}\mathbf{6 0 -} \\
\mathbf{6 9}\end{array}$ & $\begin{array}{c}\mathbf{7 0 -} \\
\mathbf{7 9}\end{array}$ & $\begin{array}{c}\mathbf{Z} \\
\mathbf{8 0}\end{array}$ & $\begin{array}{c}\text { Số } \\
\text { BN }\end{array}$ & $\begin{array}{c}\text { Tỷ lệ } \\
\mathbf{\%}\end{array}$ \\
\hline $\mathrm{A} 1$ & 9 & 12 & 5 & $\mathbf{2 6}$ & $\mathbf{3 8 , 8}$ \\
\hline $\mathrm{A} 2.1$ & 8 & 12 & 9 & $\mathbf{2 9}$ & $\mathbf{4 3 , 2 8}$ \\
\hline A2.2 & 3 & 7 & 2 & $\mathbf{1 2}$ & $\mathbf{1 7 , 9 2}$ \\
\hline Cộng & $\mathbf{2 0}$ & $\mathbf{3 1}$ & $\mathbf{1 6}$ & $\mathbf{6 7}$ & $\mathbf{1 0 0}$ \\
\hline
\end{tabular}

Loại gãy A2.1 gặp nhiều nhất $29 \quad \mathrm{BN}$ (43,28\%), đến loại A1 26 BN(38,8\%).

Kết quả nắn chỉnh góc cổ thân xương $(n=67)$.

\begin{tabular}{|c|c|c|}
\hline $\begin{array}{c}\text { Góc cố thân } \\
\text { xương }\end{array}$ & $\begin{array}{c}\text { Số bệnh } \\
\text { nhẩn }\end{array}$ & Tỷ lệ \% \\
\hline $125^{0}-130^{0}$ & 50 & 74,62 \\
\hline $120^{0} \leq 125^{0}$ & 12 & 17,91 \\
\hline $110^{0} \leq 120^{0}$ & 5 & 7,47 \\
\hline$<110^{0}$ & 0 & 0 \\
\hline Tống & $\mathbf{6 7}$ & $\mathbf{1 0 0}$ \\
\hline
\end{tabular}

Xương được nắn về đúng vị trí giải phầu, góc cổ thân $125^{\circ}-130^{\circ}$ có $50 / 67$ BN $(74,62 \%)$. Từ $120^{\circ} \leq 125^{\circ}$ có $12 / 67 \mathrm{BN}(17,91 \%)$, từ $110^{\circ} \leq$ $120^{\circ}$ có 5 BN $(7,47 \%)$.

Phân loại kết quả chung theo Nguyễn Trung Sinh 1999

\begin{tabular}{|c|c|c|c|c|}
\hline $\begin{array}{c}\text { Kết } \\
\text { quả }\end{array}$ & $\begin{array}{c}\text { Rất } \\
\text { tốt }\end{array}$ & Tốt & $\begin{array}{c}\text { Trung } \\
\text { bình }\end{array}$ & Kém \\
\hline $\mathrm{N}$ & 36 & 23 & 8 & 0 \\
\hline$\%$ & $53,73 \%$ & $34,32 \%$ & $11,95 \%$ & 0 \\
\hline
\end{tabular}

Kết quả chung của chúng tôi tốt và rất tốt chiếm $88.05 \%$, tỉ lệ đạt trung bình là $11,95 \%$ và không gặp bệnh nhân nào có kết quả xâu.

\section{BÀN LUẬN}

Đặc điểm chung của nhóm nghiên cứu: Trong nghiên cứu của chúng tôi có 41 BN trên 70 tuổi $(70,15 \%)$, tuổi trung bình $73,76 \pm 5,25$ tuổi. Theo Jonnes và cộng sự tuổi trung bình của gãy $L M C$ xương đùi từ 67 đến 76 và tỷ lệ nữ nhiều hơn nam từ 2 đến 8 lần[1]. Trong những năm gần đây, khi tuổi thọ trung bình tăng lên, gãy LMC xương đùi ngày càng nhiêuu và đang được coi như là vấn đề lớn của xã hội hiện đại. Tại các nước phát triển, gãy LMC xương đùi xảy ra chủ yếu ở độ tuổi trên 70 , hầu hết là do tai nạn sinh hoạt. Một nguyên nhân được cho là rất quan trọng đó là tình trạng thưa loãng xương. Về nguyên nhân gãy LMC xương đùi theo nghiên cứu của chúng tôi thì do tai nạn sinh hoạt chiếm tỉ lệ cao $67,17 \%$, TNGT chỉ có $25,37 \%$ và tập trung vào nhóm tuổi trẻ tai nạn lao động chỉ có $7,46 \%$. Nhóm tuổi càng trẻ thì nguyên nhân do tai nạn giao thông, do chấn thương chiếm tỉ lệ lớn hơn vì họ tham gia giao thông nhiề. Theo chiều ngược lại tuổi càng lớn thì nguyên nhân chủ yếu là tai nạn sinh hoạt mà chủ yếu là do 
ngã chiếm phần lớn và đa số là do chấn thương trực tiếp do ngã đập trực tiếp vùng mông- mấu chuyển xuống nền cứng (nền nhà, bậc thềm, sân...). Nguy cơ rất dễ bị ngã ở người cao tuổi, và khi ngã thường bị gãy xương do xương yếu, mỏng và thưa xương. Theo nghiên cứu của Karakus[2] cho thấy hơn $90 \%$ gãy đầu trên xương đùi là do té ngã. Như vậy đặc điểm về tuổi tác, giới tính và nguyên nhân trong nghiên cứu của chúng tôi cũng phản ánh đúng thực tế ở vì người cao tuổi và cũng tương tự như các tác giả khác. Người cao tuổi, loãng xương nặng, chỉ cần một chấn thương nhẹ cũng có thể bị gãy xương, đầu trên xương đùi là vùng có loãng xương và trở thành điểm yếu dễ xảy ra gãy xương.

Đặc điểm XQ của nhóm nghiên cứu: Có rất nhiêu cách phân loại trong gãy LMC xương đùi, một số tác giả đưa ra phân loại dựa trên mô tả về giải phẫu (Evans; Ramadier) một số tác giả khác đưa ra phân loại có tính chất cung cấp thông tin mang tính tiên lượng (Tronzo, Ender). Đối với gãy LMC xương đùi điều quan trong nhất liên quan đến lựa chọn phương pháp phẩu thuật, dụng cụ, phương tiện kết xương cũng như tiên lượng là phân biệt gãy vững và gãy không vững. ở trường hợp gãy vững là mảnh xương thành sau trong còn nguyên vẹn hoặc chỉ có mảnh rời nhỏ nên sau nắn chỉnh các đầu gãy tiếp xúc tốt. Gãy không vững là trường hợp có nhiêu mảnh rời hay mảnh rời lớn ở thành sau trong luôn có xu hướng sụp đổ vagus. Cách phân loại này được nhiều tác giả áp dụng như: Evans, Boyd và Griffin... Phân loại của AO là cách phân loại rất đầy đủ bao gồm mọi dạng vùng mấu chuyển[3].

Tỉ lệ về loại theo phân loại của $A O$ trong nghiên cứu của chúng tôi là $A 1: 38,8 \%, A 2.1$ : 43,28\%, A2.2: 17,92\%. Do đặc điểm của nguyên nhân chủ yếu là tai nạn sinh hoạt nên loại A1, A2.1 cao.

Phân loại AO khá chi tiết, hướng đường gãy, di lệch được xác định cụ thể có ý nghĩa trong tiên lượng và thái độ xủ lý lâm sàng về việc chọn phương tiện. Chúng tôi chọn phân loại gãy của $\mathrm{AO}$, vì cách phân loại này rõ ràng, cụ thể giúp cho phẫu thuâat viên phân loại, đánh giá chính xác mức độ tổn thương, lựa chọn được phương tiện kết xương phù hợp, tiên lượng lượng được những khó khăn trong cuộc mổ và sau mổ. Đây là cách phân loại được sử dụng phổ biến hiện nay.

Kết quả phẫu thuật: Diễn biến tại vết mổ chúng tôi có $67 / 67$ bệnh nhân liền da kỳ đâu chiếm tỷ lệ $100 \%$, không có bệnh nhân nào nhiễm khuẩn nông và nhiếm khuẩn sâu. Là do bệnh nhân được tiêm kháng sinh trước và sau phẫu thuật, phẫu thuật được thực hiện một cách nghiêm túc, công tác vô khuẩn được đảm bảo, đường mổ nhỏ ít xâm lấn, thời gian phẫu thuật ngắn tối đa và dẫn lưu kín triệt để. Sau mổ BN được chăm sóc tốt tại chỗ cũng như toàn thân và hướng dẫn luyện tập chu đáo. Kết quả nắn chỉnh giải phẫu trển $X$-quang sau mổ, chúng tôi có kết quả tốt hết di lệch Góc cổ thân xương từ $125^{\circ}-130^{\circ}$ là $74,62 \%$, chủ yếu tập trung ở loại xương độ $A 1$ và $A 2.1$. Các $B N$ còn di lệch ít chiếm $7,47 \%$ chủ yếu ở nhóm gãy kiểu $A 2.2$.

Nhóm bệnh nhân nghiên cứu với thời gian theo dõi trung bình là 8,3 tháng cho thấy kết quả chung theo tiêu chuẩn của Nguyễn Trung Sinh như sau: Rất tốt: 36/67 BN (53,73\%); Tốt: 23/67 BN (34,32\%).

Trung bình: 8/67BN (11,95\%); Kém: 0/17 BN (0\%).

\section{KẾT LUÂ̂N}

Qua nghiên cứu điều trị 67 bệnh nhân bị gãy LMC xương đùi bằng nẹp DHS có sử dụng $C$-arm trong phẫu thuật chúng tôi nhận thây tuổi trung bình của nhóm nghiên cứu là $73,76 \pm 5,25$, tỉ lệ nam giới bị gãy LMC chiếm $68,65 \%$ và nữ giới chiếm 31,35\%. Lứa tuổi từ $70-79$ tuổi bị gãy LMC chiếm nhiều nhất là 46,26\%. Nguyên nhân gãy LMC xương đùi chủ yếu là do ngã số gẫy gặp ở 35 BN(67,17\%) chỉ sau một chấn thương nhẹ, thường gặp nhất là do trượt chân ngã đập mông xuống sàn nhà. Loại gãy A2.1 gặp nhiều nhất 29 BN (43,28\%), đến loại A1 26 BN (38,8\%)

Liền vết mổ kỳ đầu: $67 / 67$ bệnh nhân $(100 \%)$. Kết quả nắn chỉnh: Xương được nắn về đúng vị trí giải phẫu, góc cổ thân $125^{\circ}-130^{\circ}$ có $50 / 67$ BN (74,62\%). Từ $120^{\circ}-<125^{0}$ có $12 / 67$ BN (17,91\%), từ $110^{\circ}-<120^{\circ}$ có $5 \mathrm{BN}(7,47 \%)$. Kết quả theo tiêu chuẩn của Nguyễn Trung Sinh của chúng tôi tốt và rất tốt chiếm $88.05 \%$, tỉ lệ đạt trung bình là $11,95 \%$ và không gặp bệnh nhân nào có kết quả xấu.

Đối với gãy LMC xương đùi nên mổ sớm khi có đủ điều kiện để tránh các biến chứng xảy ra do nằm lâu. Với những $\mathrm{BN}$ có tổn thương phối hợp hoặc có bệnh mãn tính kèm theo cần điều trị tích cực, sớm ổn định để có thể tiến hành phẫu thuật. Phẫu thuật sử dụng nẹp vít nén ép trượt (DHS) để kết hợp xương gãy liên mấu chuyển nhưng đặc biệt có sự hổ trợ quan trọng trong mổ của màn tăng sáng (C-arm) giúp cho vị trí đặt nẹp vít chính xác, xâm lấn phần mềm tối thiểu, thời gian mổ rút ngắn tối đa mang lại kết quả bước đầu rất khả quan cho bệnh nhân. 


\section{TÀI LIÊU THAM KHẢO}

1. Jonnes.O, Ozdemir.M,Saygi.B (2018) :Type II Intertrochanteric Fractures: Proximal Femoral Nailing (PFN) Versus Dynamic Hip Screw (DHS)
2. Karakus,Cetin (2016): The relationship between the type of unstable intertrochanteric femur fracture and mobility in the elderly

3. https://surgeryreference.aofoundation.org/ortho pedic-trauma/adult-trauma/proximal-femur.

\section{THỰC TRANG STRESS CỦA SINH VIÊN CHÍNH QUY NĂM CUỐI THUỘC CÁC CHUYÊN NGÀNH TAI TRƯỜNG ĐAI HOQC Y - DƯỢC THÁI NGUYÊN NĂM 2020 VÀ MộT SỐ YẾU TỐ LIÊN QUAN}

\section{TÓM TẮT}

Mục tiêu: Mô tả thực trạng stress của sinh viên chính quy năm cuối thuộc các chuyên ngành tại trường Đai học Y - dược Thái Nguyên năm 2020 và môt số yểu tố liên quan. Phương pháp nghiên cứu: nghiên cứu cắt ngang tiến hành trên 862 sinh viên chính quy năm cuối thuôc các chuyên ngành tai trường Đại học Y - dược Thái Nguyên năm 2020. Kểt quả: tỷ lể stress ở sinh viên năm cuối là 38,5\%, trong đó mức độ vừa chiếm tỷ lệ cao nhất $(12,8 \%)$, mức độ nhe chiếm tỷ lê $11,7 \%$, mức đô năng có tỷ lề là $10,1 \%$, thấp nhất là mức độ rất nặng $(3,9 \%)$. Phân bố stress theo các chuyên ngành: sinh viên ngành ĐH Dược có tỷ lệ stress cao nhất (57,3\%), sau đó là sinh viên ngành BS RHM $(47,4 \%)$, ngành $B S Đ K$ và $C N X N$ đều chiếm $37,8 \%$, ngành CNDD chiếm $34,3 \%$ và thấp nhất là sinh viên ngành BS YHDP $(18,6 \%)$. Có mối liên quan giữa tình hình tài chính, việc chia sẻ các vấn đề với bố mẹ, việc thường xuyên xảy ra mâu thuẫn với bố me hoặc anh chị em và bạn bè, áp lực học tập với tình trang stress của sinh viên.

Từ khóa: sinh viên, stress, yếu tố liên quan.

\section{SUMMARY}

THE REALITY OF STRESS OF THE FINAL YEAR STUDENT IN MANY SPECIALTIES AT THAI NGUYEN UNIVERSITY OF MEDICINE AND PHARMACY IN 2020 AND SOME RELATED FACTORS

Objective: Reflecting the reality of the final year students' stress in many specialties at Thai Nguyen University of Medicine and Pharmacy in 2020 and some relative factors. Methods: A cross-sectional study was conducted on 862 seniors at Thai Nguyen university of medicine and pharmacy in 2020. Results: $38,5 \%$ of the surveyed students had to face with stress, in which the medium level occupied the highest rate at $12,8 \%$; followed by the slight level $(11,7 \%)$, the severe level $(10,1 \%)$ and the lowest one

*Trường Đại học Y dược - Đại học Thái Nguyên Chịu trách nhiệm chính: Trân Thị Ly Email: Tranthilybg1997@gamil.com Ngày nhận bài: 24.2.2021

Ngày phản biện khoa học: 2.4.2021 Ngày duyệt bài: 13.4.2021
Trần Thị Ly*, Phạm Thị Hoa*, Lê Hoài Thu*

was the extreme level at 3,9\%. Considering the reality of stress according to specialties we found that the rate of the stress of the pharmaceutical students was the highest $(57,3 \%)$, followed by the rate of dental doctor $(47,4 \%)$, both general doctor and bachelor of test specialties had the same rate $(37,8 \%)$, bachelor of nursing accounted for $34,3 \%$ and the lowest was the preventative medicine specialty $(18,6 \%)$. There are connections between the students' stress and financial situation, sharing problems or regular conflicts with parents, siblings and friends and academic pressure.

Keywords: students, stress, related factors.

\section{I. ĐĂT VẤN ĐỀ}

Ngày nay các bạn trẻ nói chung và các bạn sinh viên nói riêng thường phải đối mặt với rất nhiêuu áp lực, đó có thể là những áp lực về tinh thân dẫn đến trạng thái mệt mỏi, căng thẳng thân kinh,... mà chúng ta hay gọi là stress. Các nghiên cứu trên thế giới đã cho thấy tỷ lệ biểu hiện stress ở sinh viên đang ở mức cao [1] [2]. Tại Việt Nam, các sinh viên trường $Y$ với nhưng gánh nặng vế học tập và nghề nghiệp trong tương lai nền khả nằng dẫn đến tình trạng stress là rất cao và đăc biệt với sinh viên năm cuối. Theo nghiên cứu tại trường đại học Y Dược thành phố Hồ Chí Minh cho thây $77 \%$ sinh viên có dấu hiệu của stress [3], nghiên cứu tại trường đại học y tế công cộng năm 2017 đã chỉ ra rằng 34,4\% sinh viên có biểu hiện stress [4]. Việc nghiên cứu tình trạng stress của sinh viên trường $Y$ đã được thực hiện ở nhiêu nước trên thế giới cũng như ở Việt Nam, tuy chưa thây có nghiên cứu về vấn đề này tai trường Đai học Y - Dược Thái Nguyên. Do đó, chúng tôi tiến hành đề tài này với mục tiêu nghiên cứu: Mô tả thực trạng stress của sinh viên chính quy năm cuôi thuộc các chuyên ngành của trường Đại học Y - dược Thái Nguyên năm 2020 và một số yêu tố liên quan.

II. ĐỐI TƯợNG VÀ PHƯƠNG PHÁP NGHIÊN CứU

1. Đối tượng nghiên cứu: Sinh viên chính 